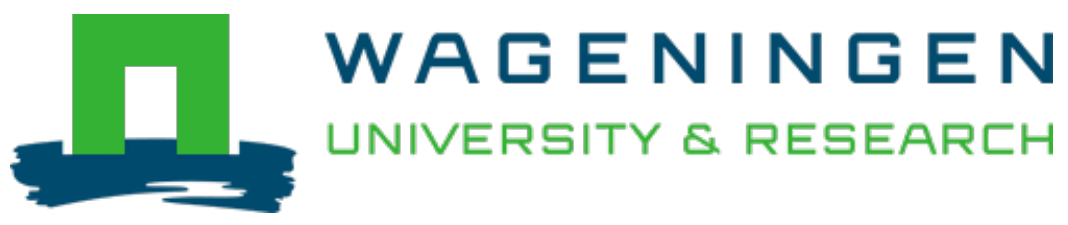

\author{
Spatial sorting and range shifts: consequences for evolutionary potential and \\ genetic signature of a dispersal trait \\ Journal of Theoretical Biology \\ Cobben, M.M.P.; Verboom, J.; Opdam, P.F.M.; Hoekstra, R.F.; Jochem, R. et al \\ https://doi.org/10.1016/j.jtbi.2015.03.019
}

This article is made publicly available in the institutional repository of Wageningen University and Research, under the terms of article $25 \mathrm{fa}$ of the Dutch Copyright Act, also known as the Amendment Taverne. This has been done with explicit consent by the author.

Article 25 fa states that the author of a short scientific work funded either wholly or partially by Dutch public funds is entitled to make that work publicly available for no consideration following a reasonable period of time after the work was first published, provided that clear reference is made to the source of the first publication of the work.

This publication is distributed under The Association of Universities in the Netherlands (VSNU) 'Article $25 \mathrm{fa}$ implementation' project. In this project research outputs of researchers employed by Dutch Universities that comply with the legal requirements of Article $25 \mathrm{fa}$ of the Dutch Copyright Act are distributed online and free of cost or other barriers in institutional repositories. Research outputs are distributed six months after their first online publication in the original published version and with proper attribution to the source of the original publication.

You are permitted to download and use the publication for personal purposes. All rights remain with the author(s) and / or copyright owner(s) of this work. Any use of the publication or parts of it other than authorised under article $25 \mathrm{fa}$ of the Dutch Copyright act is prohibited. Wageningen University \& Research and the author(s) of this publication shall not be held responsible or liable for any damages resulting from your (re)use of this publication.

For questions regarding the public availability of this article please contact openscience.library@,wur.nl 


\title{
Spatial sorting and range shifts: Consequences for evolutionary potential and genetic signature of a dispersal trait
}

\author{
M.M.P. Cobben ${ }^{\mathrm{a}, \mathrm{b}, *}$, J. Verboom ${ }^{\text {c }}$, P.F.M. Opdam ${ }^{\text {c,d }}$, R.F. Hoekstra ${ }^{\mathrm{e}}$, \\ R. Jochem ${ }^{\text {c }}$, M.J.M. Smulders ${ }^{\text {b }}$ \\ a Netherlands Institute of Ecology (NIOO-KNAW), Droevendaalsesteeg 10, 6708 PB Wageningen, The Netherlands \\ ${ }^{\mathrm{b}}$ Wageningen UR Plant Breeding, PO Box 16, 6700 AA Wageningen, The Netherlands \\ ' Alterra, Wageningen UR, PO Box 47, 6700 AA Wageningen, The Netherlands \\ ${ }^{\mathrm{d}}$ Land Use Planning Group, Wageningen University, PO Box 47, 6700 AA Wageningen, The Netherlands \\ e Laboratory of Genetics, Wageningen University, PO Box 16, 6700 AA Wageningen, The Netherlands
}

\section{H I G H L I G H T S}

- We simulate a species' range shift under climate change.

- The allele for low dispersal rate is prone to extinction at the retracting margin.

- Recovery of the original genotype distribution after the shift takes a long time.

- The time to recovery depends on the total displacement of the climate optimum.

\section{A R T I C L E I N F O}

\section{Article history:}

Received 17 December 2014

Received in revised form

11 March 2015

Accepted 12 March 2015

Available online 24 March 2015

Keywords:

Metapopulation

Individual-based model

Climate change

\begin{abstract}
A B S T R A C T
Species are shifting their ranges under climate change, with genetic and evolutionary consequences. As a result, the spatial distribution of genetic diversity in a species' range can show a signature of range expansion. This genetic signature takes time to decay after the range stops expanding and it is important to take that lag time into account when interpreting contemporary spatial patterns of genetic diversity. In addition, the return to spatial equilibrium on an ecologically relevant timescale will depend on migration of genetic diversity across the species' range. However, during a range shift alleles may go extinct at the retracting range margin due to spatial sorting. Here we studied the spatial pattern of genotypes that differ in dispersal rate across the species range before, during and after a range shift, assessed the effect of range retraction on this pattern, and quantified the duration of the ephemeral genetic signature of range expansion for this trait. We performed simulation experiments with an individual-based metapopulation model under several contemporary climate change scenarios. The results show an increase of the number of individuals with high dispersal rate. If the temperature increased long enough the allele coding for low dispersal rate would go extinct. The duration of the genetic signature of range expansion after stabilisation of the species' distribution lasted up to 1200 generations after a temperature increase for 60 years at the contemporary rate. This depended on the total displacement of the climate optimum, as the product of the rate of temperature increase and its duration. So genetic data collected in the field do not necessarily reflect current selection pressures but can be affected by historic changes in species distribution, long after the establishment of the current species' range. Return to equilibrium patterns may be hampered by loss of evolutionary potential during range shift.
\end{abstract}

c) 2015 Elsevier Ltd. All rights reserved.

\footnotetext{
* Corresponding author at: Netherlands Institute of Ecology (NIOO-KNAW),

Droevendaalsesteeg 10, 6708 PB Wageningen, The Netherlands.

E-mail addresses: m.cobben@nioo.knaw.nl (M.M.P. Cobben), jana.verboom@wur.nl (J. Verboom), paul.opdam@wur.nl (P.F.M. Opdam), rolf.hoekstra@wur.nl (R.F. Hoekstra), rene.jochem@wur.nl (R. Jochem), rene.smulders@wur.nl (M.J.M. Smulders).
}

\section{Introduction}

Species are shifting their ranges under climate change (Chen et al. 2011; Parmesan and Yohe, 2003), which has genetic and evolutionary consequences (Excoffier et al., 2009; Kubisch et al., 2014; Parmesan, 2006). The genetic diversity present at the expanding range margin is smeared across the landscape on the expansion wave (Excoffier and Ray, 2008). This is the case for neutral as well as adaptive genetic 
variation (Cobben et al., 2012a, 2011; Edmonds et al., 2004; Hewitt, 1996; Ibrahim et al., 1996; Klopfstein et al., 2006; Travis et al., 2007, 2010). Under these conditions, the genetic configuration of the newly colonised populations is largely the result of the demographic process under range expansion, and not of selection (Travis et al., 2007), although some traits are selected for under range expansion, particularly the ability to disperse and traits related to population growth rate (Hill et al., 2011; Moreau et al., 2011; Phillips et al., 2010).

With regard to the ability to disperse, both theoretical and empirical studies report an increased dispersal capacity as a result of spatial sorting under range expansions (e.g. Burton et al., 2010; Phillips et al., 2006; Thomas et al., 2001; Travis and Dytham, 2002; Travis et al., 2013). Good dispersers gather at the range margin and from there they colonise new territory, while the poor dispersers lag behind. This eventually leads to a spatial gradient in dispersal capacity across the species' range, which can be regarded as a genetic signature of range expansion (Phillips et al., 2010). After the range stops expanding, it takes time for such a genetic signature of range expansion to decay, especially when the variation for these traits needs to migrate from the centre of the range or to develop through de novo mutations (Dytham et al., 2014; Phillips et al., 2010). During that time period populations are in spatial disequilibrium as a result of the past range expansion. In a time when many investigators are gathering genetic data from natural populations to study selection pressures and microevolution, accounting for different explanations of genetic make-up is crucial (Currat et al., 2006; Ray and Excoffier, 2009). Investigating the genetic signature of range expansion is therefore of importance for the interpretation of contemporary spatial patterns in genetic diversity.

Particularly for a dispersal trait, it can be expected that the decay of this genetic signature of range expansion may take a long time: after the range expansion stops the net effect of selection will be for lower dispersal capacity, yet low dispersal genotypes are by definition slow dispersers. Kubisch et al. (2010) showed that the establishment of genotypes with low dispersal rates after range expansion is the result of the migration of variation, and does not involve the establishment of new, beneficial mutations. In their study we see a slow return to equilibrium dispersal rate values at the expanding range margin after range expansion, but this result is not specifically quantified or discussed. In contrast, Henry et al. (2014) claimed a fast return to equilibrium values after range expansion, resulting from selection for beneficial mutations. In a mechanistically more realistic model, Dytham et al. (2014) showed that the state of spatial disequilibrium can last for a substantial time period after the range expansion. In addition, they observed that the speed of range expansion depends on selection for existing variation rather than for new variation due to mutations, even under a high mutation rate (Dytham et al., 2014). This is in line with theory and empirical data on micro-evolution, in which evolutionary changes that are relevant at ecological timescales depend on changes in allele frequencies rather than on new mutations. However, none of the above studies have explicitly discussed or tried to quantify the time period during which populations are in spatial disequilibrium.

Under a climate change scenario with continued temperature increase, many species' ranges are expected to retract at the margin with the deteriorating thermal conditions, resulting in a range shift rather than a range expansion (Gillings et al., 2015; Thomas et al., 2006). This means that slow dispersers might be lost as a result of spatial sorting and subsequent extinction of populations at the retracting margin (Cobben et al., 2012a; Cobben et al., 2011), while return to equilibrium values after range expansion likely depends on such existing genetic diversity as argued above (Dytham et al., 2014; Kubisch et al., 2010). Many studies have reported increased dispersal under range expansion (e.g. Burton et al., 2010; Phillips et al., 2006; Thomas et al., 2001; Travis and Dytham, 2002; Travis et al., 2013), but little attention has been given to the consequences of a retracting range margin for dispersal traits (but see Henry et al., 2014).
In this paper we investigated how range shifts affect the distribution of different genotypes coding for low, medium and high rates of dispersal across the species range. In addition, we studied the duration of the ephemeral genetic signature of range expansion. For both, we used a mechanistically realistic model of a range shifting species under climate change. We simulated a period of temperature increase in several scenarios, during and after which we registered the distribution of the different dispersal rate genotypes in the landscape up until 5000 years after model initialisation. To warrant sufficient variation in the existing genetic diversity under stationary conditions, we employed diploid inheritance, fragmented habitat and temperature variability. The genetic architecture was designed to get a clear signature of spatial sorting as well as distinct differences between phenotypes.

\section{Methods}

We used a spatially explicit, individual-based simulation model of a sexually reproducing species with overlapping generations. The model is called METAPHOR (Verboom et al., 2001; Vos et al., 2001) and has previously been extended to allow for stochastic temperature increase (Schippers et al., 2011) and with a genetic module for neutral (Cobben et al., 2011, 2012b) and adaptive traits (Cobben et al., 2012a). It was parameterised based on empirical data for the middle spotted woodpecker (Dendrocopus medius), a woodland bird (Hagemeijer and Blair, 1997; Kosenko and Kaigorodova, 2001; Kosinski and Ksit, 2006; Kosinski et al., 2004; Michalek and Winkler, 2001; Pasinelli, 2000; Pettersson, 1985). Table 1 gives an overview of the parameters used. For the current study we allowed the dispersal rate to be adaptive and investigated the spatial distribution of the allele frequencies at the dispersal gene during and after range shift.

\subsection{Landscape}

The landscape was $15 \mathrm{~km}$ wide (horizontal axis) by $2000 \mathrm{~km}$ long (vertical axis). In horizontal direction the borders were merged, creating a (vertical) tube. The landscape contained 3000 randomly distributed habitat patches, equalling a total of $5 \%$ habitat area. In vertical direction, a Gaussian temperature curve was shifting across the landscape at various speeds, and with a standard deviation of $140 \mathrm{~km}$ (see Appendix A). This temperature was used to determine the local habitat quality and each row in the landscape was as such characterised by a time-specific habitat quality $q[0 . .1]$, being 1 at the peak of the distribution and 0 outside the curve area. We used three temperature increase scenarios, based on work by the IPCC (2013), of a respective temperature increase of $1^{\circ} \mathrm{C}, 2{ }^{\circ} \mathrm{C}$ and $4{ }^{\circ} \mathrm{C}$ by the year 2100 , resulting in equivalent isocline shift rates of 2,4 and $8 \mathrm{~km}$ per year, respectively (see Appendix A).

\subsection{Population demography}

The patches in the landscape were inhabited by individuals that were characterised by their sex, and their dispersal alleles (see below under Genetics). The yearly life cycle consisted of recruitment, dispersal, and survival, in this order. Per patch, in each year, the number of offspring per unique pair of individuals of opposite sex was dependent on local habitat quality $q$ and population density $d$, following:

$R=R_{d 0 q 1}\left(1-\left(1-\frac{R_{d 0 q 0}}{R_{d 0 q 1}}\right)(1-q)\right)\left(1-\left(1-\frac{R_{d 1 q 1}}{R_{d 0 q 1}}\right) d\right)$

with $R_{d 0 q 1}$ is the number of offspring at $d=0$ and $q=1$, and similar for $R_{d 0 q 0}$ and $R_{d 1 q 1}$. 
Table 1

Model parameters and variables used.

\begin{tabular}{|c|c|c|c|}
\hline Description & Value & Unit & Symbol \\
\hline Recruitment at density $=0$ and quality $=1$ & 2.4 & offspring/female & $R_{d 0 q 1}$ \\
\hline Recruitment at density $=1$ and quality $=1$ & 1 & offspring/female & $R_{d 1 q 1}$ \\
\hline Recruitment at density $=0$ and quality $=0$ & 0 & offspring/female & $R_{d 0 q 0}$ \\
\hline Maximum dispersal distance & 15 & $\mathrm{~km}$ & \\
\hline Dispersal probability genotype AA & 0.0 & year $^{-1}$ & \\
\hline Dispersal probability genotype $A B$ & 0.1 & year $^{-1}$ & \\
\hline Dispersal probability genotype BB & 0.2 & year $^{-1}$ & \\
\hline Survival probability at density $=1$ and quality $=1$ & 0.6 & year $^{-1}$ & $s_{d 1 q 1}$ \\
\hline Survival probability at density $=0$ and quality $=1$ & 0.8 & year $^{-1}$ & $s_{d 0 q 1}$ \\
\hline Survival probability at density $=1$ and quality $=0$ & 0.35 & year $^{-1}$ & $s_{d 1 q 0}$ \\
\hline Survival standard deviation & 0.15 & year $^{-1}$ & \\
\hline Mutation rate & $10^{-6}$ & generation $^{-1}$ & \\
\hline Number of patches & 3000 & & \\
\hline Patch carrying capacity & 20 & Individuals & $K$ \\
\hline Temperature isocline speed & $2,4,8$ & $\mathrm{~km} \mathrm{yr}^{-1}$ & $T$ \\
\hline Weather variability & 140 & $\mathrm{~km}$ & $\sigma_{d}$ \\
\hline Initial temperature optimum location & 400 & $\mathrm{~km}$ from the south edge & $Y_{o p t, 0}$ \\
\hline
\end{tabular}

Table 2

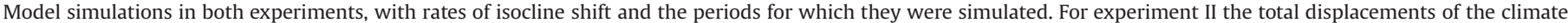
optimum after the period of temperature increase are given.

\begin{tabular}{|c|c|c|c|}
\hline Rate of isocline shift $\left(\mathrm{km} \mathrm{yr}^{-1}\right)$ & Experiment I & Experiment II & \\
\hline & Stopped after (years) & Stopped after (years) & Optimum displacements $(\mathrm{km})$ \\
\hline 2 & 500 & $50,100,200$ & $100,200,400$ \\
\hline 4 & 500 & $30,60,120$ & $120,240,480$ \\
\hline 8 & 500 & $10,20,60$ & $80,160,480$ \\
\hline
\end{tabular}

The individual dispersal rate depended on its diploid genotype and can be low (zero), medium (0.1) or high (0.2), indicating its yearly dispersal probability. Upon dispersal, individuals could leave their patch in every direction in a straight line, and were then assigned to the first patch they encountered within their maximum dispersal distance of $15 \mathrm{~km}$. The individual survival probability depended on population density $d$ and habitat quality $q$

$s=s_{d 0 q 1}\left(1-\left(1-\frac{s_{d 0 q 0}}{s_{d 0 q 1}}\right) q\right)\left(1-\left(1-\frac{s_{d 1 q 1}}{s_{d 0 q 1}}\right)(1-d)\right)$

with $s_{d 0 q 1}$ is survival rate at $d=0$ and $q=1$, and similar for $s_{d 0 q 0}$ and $s_{d 1 q 1}$.

\subsection{Genetics}

There were two alleles at the dispersal locus. Allele A signified zero dispersal rate and allele $\mathrm{B}$ coded for 0.2 dispersal rate (i.e. there was a 20 percent chance that an individual left the habitat patch in which it was born). The individuals were diploid and the alleles codominant. The actual probability of dispersal was calculated as the arithmetic mean of the alleles that they had randomly inherited from each parent: genotype $A A$ is a dispersal rate of $0, A B$ is 0.1 dispersal rate and $B B$ is a dispersal rate of 0.2 . Pilot runs included additional alleles 1 . with higher dispersal rates, but these were never maintained beyond model initiation, and 2 . with finerscaled rates, many of which were lost in more or less random patterns, and thus blurring the signal of spatial sorting. Each allele could mutate at a rate of $10^{-6}$ (Nachman and Crowell, 2000) to the other allele. Evolution in this genetic model thus depended mostly on standing genetic variation, but had clear differences between phenotypes, while the codominance allowed the spread of the A allele in AB individuals (Bell and Aguirre, 2013; Schluter and Conte, 2009; Van Belleghem et al., 2014).

\subsection{Simulation experiments}

At initialisation of the model, all habitat patches were filled with 10 adult individuals, equalling half the carrying capacity $K$. Each individual was randomly given two dispersal alleles. The temperature optimum $Y_{\text {opt }}$ was initialised at $400 \mathrm{~km}$ from the southern landscape edge. After initialisation the model was run for 500 generations, equalling 500 years, to establish equilibrium population demography and dispersal rate values. After this burn-in period we applied the stochastic temperature increase for 500 years at three isocline speeds of $2 \mathrm{~km} \mathrm{yr}^{-1}, 4 \mathrm{~km} \mathrm{yr}^{-1}$ and $8 \mathrm{~km} \mathrm{yr}^{-1}$. In a second experiment we used the same three different isocline shift rates, but combined with three time periods of temperature increase each, and monitored the population establishment and the distribution of genotypes for 5000 years afterwards (see Table 2). We performed 10 replicate simulations for both experiments. Additional control simulations included different standard deviations of the mean speed of the temperature curve of zero and $280 \mathrm{~km}$, and a different mutation rate of $10^{-6}$.

\subsection{Analysis}

We summed the average number of genotypes over 10 replicate simulations in landscape blocks of $50 \mathrm{~km}$ in vertical direction. The equilibrium genotype distribution was defined as the average number of individuals of each genotype in each $50 \mathrm{~km}$-block across all replicates of all simulations in year 500 (the year in which we start the temperature increase, so after the burn-in phase and prior to any disturbances). To quantify the deviation from the equilibrium range size and location after the stabilisation of the temperature (Deviation I), we calculated in each year and each $50 \mathrm{~km}$-block the sum of the absolute differences in total number of individuals, corrected for the location of the climate 
optimum (which is moving during the period of temperature increase). Similarly, to quantify the deviation from the equilibrium genotype distribution after the stabilisation of the temperature, we calculated in each year and each $50 \mathrm{~km}$-block the sum of the absolute differences in individual numbers of each of the different genotypes, corrected for the location of the climate optimum (Deviation II)

Deviation $I, t=\sum_{i=1}^{15}\left(\left|\sum_{X=1}^{3}\left(N x_{i, t=0}\right)-\sum_{X=1}^{3}\left(N x_{i, t}\right)\right|\right)$

Deviation II, $t=\sum_{X=1}^{3}\left(\sum_{i=1}^{15}\left(\left|N x_{i, t=0}-N x_{i, t}\right|\right)\right)$

with number of individuals $N$ of genotype $X(\mathrm{AA}, \mathrm{AB}$ or $\mathrm{BB})$ in range block $i$ north of the climate optimum, with the location of the climate optimum dependent on time and simulation scenario.

By comparing these two deviations for all years after the stabilisation of the temperature, we could see the difference between the moment that the full species range is re-established after climate change stops and the moment that the equilibrium genotype distribution is re-established. This difference in time was the period in which the observed genotype distribution in the species range is the consequence of past range expansion, the so-called ephemeral signature of range expansion, and it was not indicative of current and local selection pressures.

\section{Results}

\subsection{Loss of the A allele at the trailing edge}

At the end of the burn-in phase, so under equilibrium conditions, the metapopulation consisted of individuals with dispersal rates of $0,0.1$ and 0.2 (genotypes $\mathrm{AA}, \mathrm{AB}$ and $\mathrm{BB}$ respectively; Fig. 1 year 0 ). All three genotypes were present in the total range but the individuals with 0 dispersal rate $(\mathrm{AA})$ dominated the centre of the range, while the 0.2 individuals $(\mathrm{BB})$ had the highest frequency in the margins, where habitat quality and population densities were lower. The 0.1 individuals $(\mathrm{AB})$ took an intermediate position. The control simulations showed a comparative increase in numbers of dispersive genotypes with increasing standard deviations of the mean speed of the temperature curve, but overall decreasing population numbers (Fig. S1 in Appendix B).

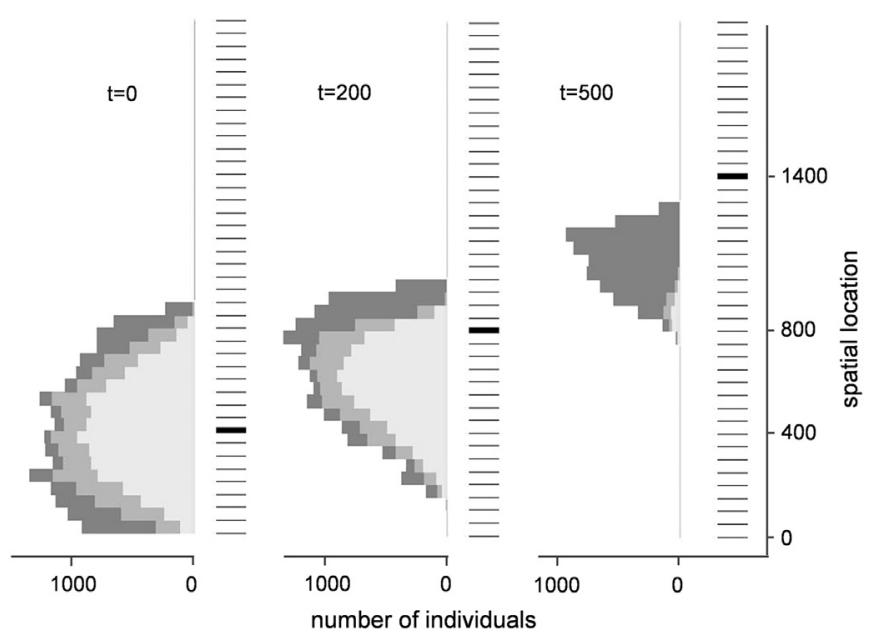

Fig. 1. The distributions of the 0 (light grey), 0.1 (medium grey), and 0.2 (dark grey) dispersal rate individuals in time in the landscape under the range shift caused by the temperature isocline shift rate of $2 \mathrm{~km} \mathrm{yr}^{-1}$, stopped after 500 years. The bold black bars indicate the spatial locations of the average temperature optimum in the specific years.

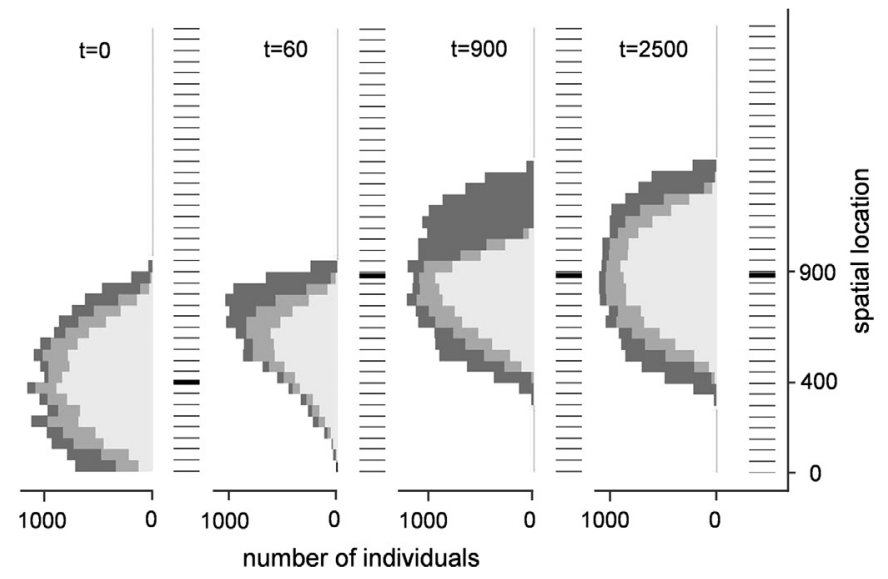

Fig. 2. The distributions of the 0 (light grey), 0.1 (medium grey), and 0.2 (dark grey) dispersal rate individuals in time in the landscape under the range shift caused by the temperature isocline shift rate of $8 \mathrm{~km} \mathrm{yr}^{-1}$, stopped after 60 years. The bold black bars indicate the spatial locations of the average temperature optimum in the specific years.

The original distribution of the populations and the genotypes within the metapopulation changed under the range shift that was induced by the temperature increase in the first experiment (Fig. 1). The range shifted, but not as fast as the climate optimum moved, and this lag resulted in a decline in the metapopulation size in time. The decline was faster with increasing speed of the climate optimum and an increasing standard deviation of this mean speed across years (Fig. S1 in Appendix B). In addition, there was an increase of the proportion of 0.2 dispersal rate individuals and the relative size of the area where they lived, at the expanding edge of the metapopulation. The number of lower dispersal rate individuals decreased and eventually the A allele went extinct as the habitat quality in the southern populations fell below the threshold value (Fig. 1 year 500). This pattern occurred in all simulations in which the metapopulation persisted sufficiently long (e.g. Fig. S1 in Appendix B).

\subsection{The genetic signature of range shift}

In experiment 2, once the temperature stabilised, the distribution of the genotypes re-established their equilibrium, but only after a certain amount of time (Fig. 2). This amount of time depended on the total displacement of the temperature optimum, so the speed of the isotherm shift multiplied by the number of years of temperature increase. This displacement also determined the shape of the deviation curve (deviation II being the measure for how far the metapopulation was from spatial equilibrium with regard to the distribution of the different genotypes), with a typical initial increase in the genotype distribution deviation for large displacements (Fig. 3c). The genotype distribution deviation was always larger than the range deviation (Fig. 3), but for small displacements the lines ran in parallel (Fig. 3a). For intermediate displacements, both deviations converged towards equilibrium values, with the range deviation levelling off first (Fig. 3b). This means that when the range reached its equilibrium size, the spatial pattern of the different dispersal genotypes was not yet in the equilibrium situation.

\section{Discussion}

We have investigated how range shifts affect the distribution of genotypes of different dispersal rates across the species range. The combination of spatial sorting and range retraction could lead to the 


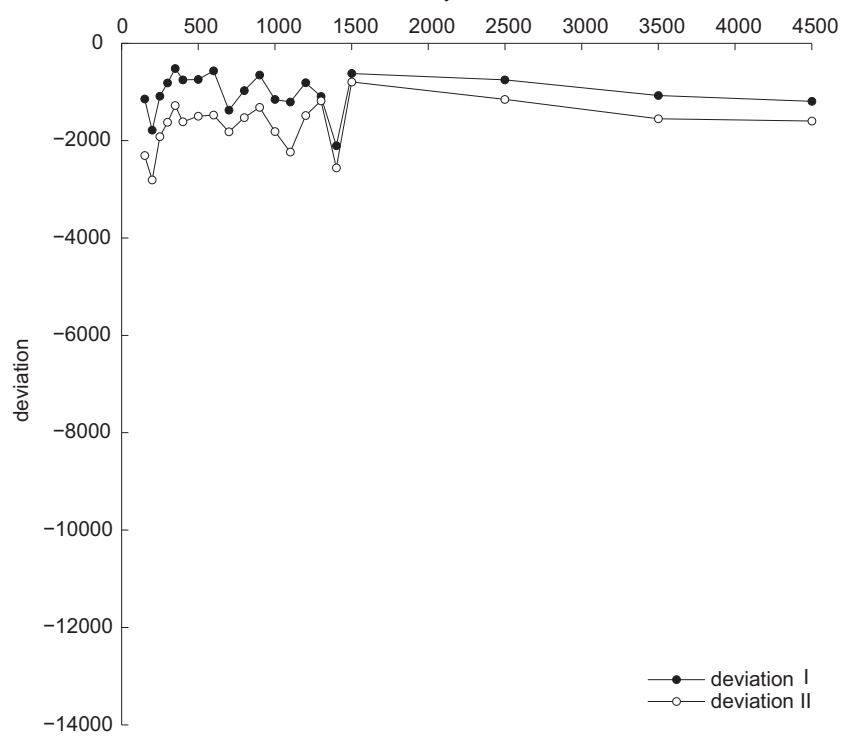

b

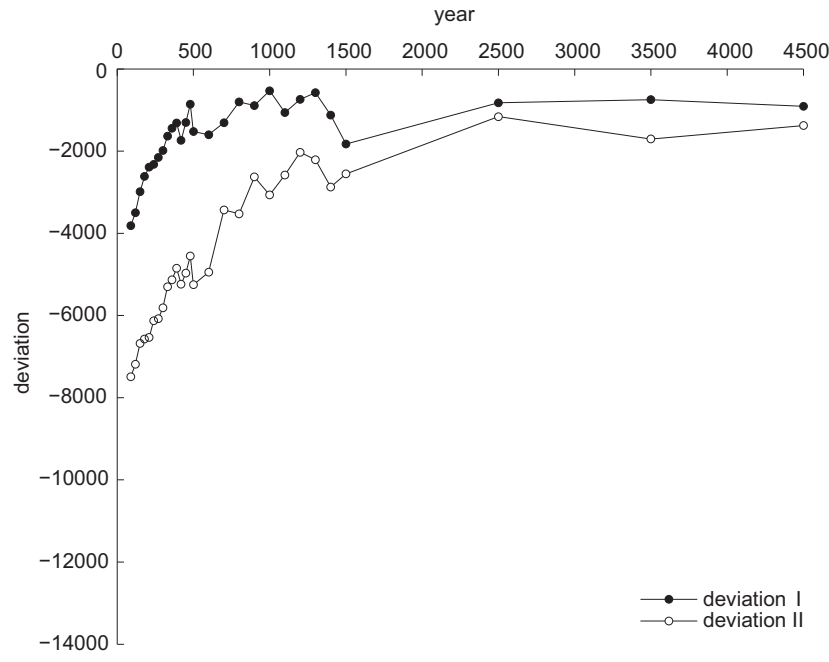

C

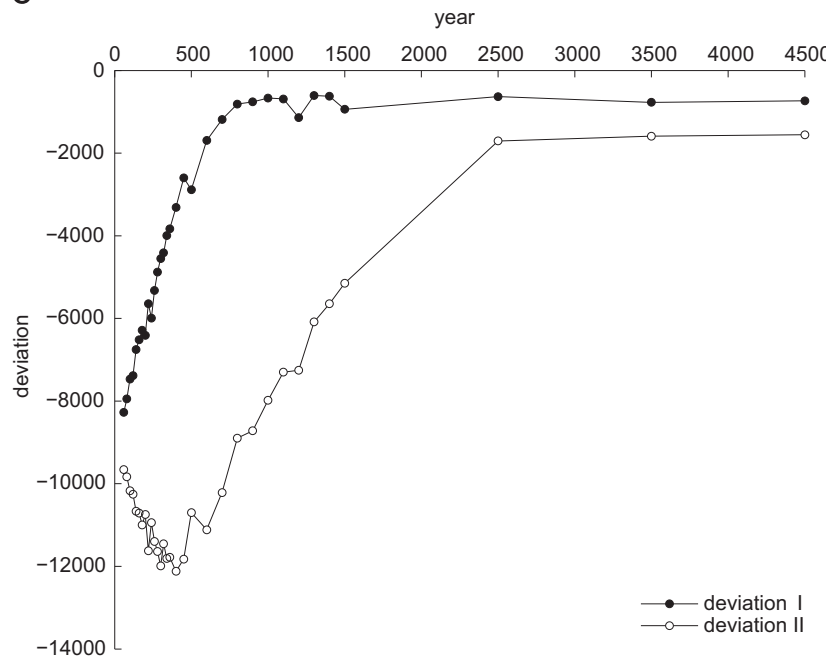

Fig. 3. The range size deviation of total numbers of individuals in time (deviation I, -•-) and the genotype distribution deviation (deviation II, - - ) in time since the year of temperature stabilisation for every scenario. The deviations are calculated as the sum of the absolute differences in numbers of individuals between the equilibrium distribution and the distribution in each year, per $50 \mathrm{~km}$-block. (a) Scenario of $2 \mathrm{~km} \mathrm{yr}^{-1}$ isocline shift for 50 years, (b) Scenario of $4 \mathrm{~km} \mathrm{yr}^{-1}$ isocline shift for 60 years, (c) Scenario of $8 \mathrm{~km} \mathrm{yr}^{-1}$ isocline shift for 60 years. extinction of the A allele, coding for low dispersal rate. When the temperature stabilised before the extinction of the A allele, the equilibrium spatial distribution of genotypes was able to recover. This, however, took an extensive amount of time, dependent on the total displacement of the temperature optimum for the investigated range of temperature increase rates. We expected that for low rates of temperature increase the genotype distribution would differ less from the equilibrium distribution under range shift, because then the selection pressures hardly change compared to a stable range. It is thus important to note that for the investigated system any realistic scenario of the rate of temperature increase under climate change had an effect on the spatial distribution of the genotypes. As such, recovery time here did not depend on the rate of temperature increase per se, but on the final total displacement of the temperature optimum. After the range shift was completed and the species' range had reached its equilibrium size, it took up to 20 times the duration of the temperature increase period before the spatial distribution of genotypes was at equilibrium. Although the genetic signature of range expansion is ephemeral, it can affect the spatial distribution of genotypes in the landscape for a long time period after the range stops expanding. This is important for the interpretation of genetic field data, since signatures of adaptive evolution in genetic data can mimic signatures of range expansion (Currat et al., 2006; Ray and Excoffier, 2009).

The metapopulation in equilibrium consisted of individuals with 0 , 0.1 , and 0.2 dispersal probability. The observed gradient of increasing dispersal rate from the core of the metapopulation to the range margins at equilibrium was as anticipated, as dispersal is essential at the margin due to the variable habitat quality, but only occasionally beneficial in the range core as a result of the high densities there (Clobert et al., 2004; Ronce, 2007). This led to a frequency-dependent selection, with a large proportion of non-dispersers and lower proportions of dispersive individuals in the core of the range. Control simulations initialised with additional alleles coding for higher dispersal rates, showed that the relative costs of dispersal were too high anywhere across the range for their persistence in the metapopulation at equilibrium. During the range shift the relative number of individuals with 0.2 dispersal rate increased as a result of spatial sorting (Shine et al., 2011). Again, in control simulations allowing for mutations with higher dispersal rates, we observed that such mutations could arise, but they never managed to establish themselves in the population during range shift.

While most studies focus on the evolution of dispersal traits under range expansion (Excoffier et al., 2009; Kubisch et al., 2011; Shine et al., 2011; Thomas et al., 2001; Travis and Dytham, 2002), we have here used a range shift scenario. We showed that in the retracting part of the range the genetic variation coding for lower dispersal rates may go extinct (Fig. 1). As soon as the lower dispersal individuals were confined to populations near the southern range margin where local selection favours higher dispersal, there was no chance of recovery for the A allele. This happened even though the metapopulation under equilibrium conditions consisted for more than two thirds of individuals carrying an A allele, so with 0 and 0.1 dispersal rates (Fig. 1). Such loss of genetic variation at the trailing edge of a shifting metapopulation is a so far non-described consequence of spatial sorting (Shine et al., 2011; Travis and Dytham, 2002). While spatial sorting is usually referred to as the phenomenon that dispersive genotypes gather at the expanding range margin (Phillips et al., 2010; Shine et al., 2011), our results indicate that this concept may be broadened to include the confinement and possible extinction of poor disperser alleles at the retracting range margin under range shift. This may cause a range-wide loss of adaptive genetic variation (Cobben et al., 2012a; Henry et al., 2014). Whether such a phenomenon can be or has been observed in the field we do not know. While the importance of rear edge populations for the conservation of species genetic diversity has been noted (Hampe and Petit, 2005), this 
concerned populations that are older than the populations in the core and leading range margin and have persisted in an ice age refugium. In addition, loss of genetic diversity in small and isolated populations as a result of genetic drift is a well-established theory and has been observed in empirical studies as well (Pearson et al., 2009). However, observing the loss of genetic diversity as a result of spatial sorting would require a well-advanced range retraction, while the first retractions have only been observed recently (Gillings et al., 2015; Thomas et al., 2006). Historical and ongoing range contractions are plentiful (Channell and Lomolino, 2000; Laliberte and Ripple, 2004; Rodríguez, 2002), but are not necessarily associated with a range shift, and information about the adaptive genetic composition of such species' ranges is not available at the moment (but for neutral diversity see Koen et al., 2014).

The disequilibrium distribution of genotypes after the range stops expanding, and its long duration may reduce the species' fitness (Cobben et al., 2012a; Dytham et al., 2014) as it represents a form of maladaptation. Here we showed in an ecologically realistic model that if the variation for a specific trait needs to migrate or develop by de novo mutations, and the trait itself is related to a reduced tendency to disperse, this period of disequilibrium may last for hundreds or even thousands of years. Control simulations with an increased mutation rate of $10^{-4}$ seldom showed the establishment of a low dispersive mutation which then increased the return rate to equilibrium. Similar studies report a lengthy phase of spatial disequilibrium and a dependency on existing genetic diversity rather than of new mutations (Dytham et al., 2014; Kubisch et al., 2010). In contrast, Henry et al. (2014) mention a fast return to equilibrium distributions of dispersal rates after range expansion due to the establishment of beneficial mutations. They however used a high mutation rate of $10^{-3}$, a larger model population, and haploid inheritance. Under diploid inheritance, the phenotypic effect of a beneficial mutation is diluted in heterozygotes. As long as the allele frequency is low the allele will exist almost completely within heterozygotes. In diploids the return to spatial equilibrium will therefore depend on the migration of existing (standing) genetic variation (Schluter and Conte, 2009; Van Belleghem et al., 2014) rather than on mutations.

Burton et al. (2010) showed in a modelling study that the presence of a competing species in the region to be colonised can greatly reduce the extent to which dispersal traits are selected for in populations at the leading edge. Additionally, in a large metapopulation as the one we modelled, you may expect adaptation to local environmental conditions, although for small subpopulations such adaptation is less common (Leimu and Fischer, 2008). Bourne et al. (2014) showed that the spread of a genotype that is beneficial under climate change only facilitates population rescue when there is no strong local selection against non-specialists. Such local adaptation could therefore be of consequence (Kubisch et al., 2013), especially when there is genetic linkage between the underlying genes or it essentially involves the same traits (Brown et al., 2007).

With continuously changing environmental conditions and land use patterns we can safely assume that many species (or species traits) are permanently in disequilibrium. In Europe, even now, some species are still expanding their ranges after the last glacial maximum. This means that observed phenotypes in the field cannot be assumed to perfectly reflect the local and current selection pressures (Currat et al., 2006; Edmonds et al., 2004; Klopfstein et al., 2006; Lindström et al., 2013; Ray and Excoffier, 2009). However, field studies investigating changing local population composition in the period after colonisation have shown that less dispersive phenotypes can be found within years (Lindström et al., 2013) to decades (Thomas et al., 2001) after initial colonisation. This could be the result of the genetic architecture and heritability of the dispersal trait, or of trade-offs with other traits. For the cane toads e.g. (in Lindström et al., 2013) the dispersal capacity is the result of a combination of many different traits (Phillips et al., 2010), which are combined during spatial sorting (Shine et al., 2011). The individuals that have replaced the fast dispersers within eight years after initial colonisation had about half of the dispersal distance of the pioneer toads (Lindström et al., 2013), and there was a continuous strong selection against fast dispersal in these toads (Brown et al., 2007). Dispersal traits are very diverse, and it is no exception that they are polygenic, although heritability is mostly greater than 0.3 (Ronce, 2007). Conditional dispersal has been observed (Clobert et al., 2004; Donohue, 1999; Imbert and Ronce, 2001), but often the relative role of genetic changes and plasticity in changes of dispersal phenotypes is unclear (Ronce, 2007). We have modelled dispersal as a single gene trait and completely heritable, in line with particular empirical evidence (Haag et al., 2005; Roff, 1986; Van Belleghem et al., 2014), to quantify the duration of the genetic signature of range expansion for a trait for which the variation either needs to migrate or mutate. Control simulations including more alleles showed qualitatively similar (yet less distinct) patterns and equal recovery times. If the low dispersive $A$ allele was recessive (Roff, 1986), the $A B$ and $B B$ genotypes would have the same phenotype of 0.2 dispersal rate. Additionally, the $A B$ genotype was then expected to be present at low frequencies at the range margin under stable conditions (Wright, 1969). This may be sufficient to prevent the colonisation lag for the A allele and in any case likely shortens the period of spatial disequilibrium. Increasing complexity of genetic architecture to include multiple loci or regulator genes, or including multiple traits might further influence spatial disequilibrium patterns and evolutionary potential and remains an interesting field of future investigation. The current study shows that co-dominant heritable genetic variation for low dispersal rates on a single gene can cause a long period of spatial disequilibrium and loss of evolutionary potential under range shifts due to spatial sorting.

\section{Acknowledgements}

We like to thank several anonymous referees for constructive and useful comments that have contributed to the improvement of this manuscript. This research was supported by the Netherlands' Ministry of Economic Affairs, Agriculture, and Innovation through its strategic research program: "Sustainable spatial development of ecosystems, landscapes, seas and regions" (Projects KB-01-007-001 and KB-01007-013), by the Netherlands' National Research Programme Climate changes Spatial Planning (http://www.klimaatvoorruimte.nl/) as Project A2.4, and by the Open Programme of the Netherlands Organisation of Scientific Research (NWO).

\section{Appendix A}

We used three temperature increase scenarios, based on work by the (IPCC, 2013), of a respective temperature increase $I$ of $1{ }^{\circ} \mathrm{C}, 2^{\circ} \mathrm{C}$ and $4{ }^{\circ} \mathrm{C}$ by the year 2100 . When translating these scenarios to temperature isocline shift rates, we assumed that the simulated metapopulation was situated along the European Atlantic coast. The HadleyCentre (2003) predicts no regional differences in change of temperature within this stretch of coast for the year 2080. We therefore assumed a similar rate of temperature increase across the simulated landscape. Unaffected by mountain ranges, this coast line has a temperature gradient $G$ of $0.0042{ }^{\circ} \mathrm{C}$ per $\mathrm{km}$ (Schippers et al., 2011). The current average standard deviation of the average temperature $\sigma_{t}$ in this region is $0.59{ }^{\circ} \mathrm{C}$ (Schippers et al., 2011). We used the temperature gradient to convert the explored temperature increase rates and the yearly temperature variability, in ${ }^{\circ} \mathrm{C}$ per year and ${ }^{\circ} \mathrm{C}$ respectively, to geographical distances.

This leads to the speed with which temperature isoclines travel north $\left(T \mathrm{~km} \mathrm{yr}^{-1}\right)$ and the yearly fluctuation of these lines $\left(\sigma_{d} \mathrm{~km}\right)$, by using

$T=I / G$, 
and

$\sigma_{d}=\sigma_{t} / G$

Following from these, the three temperature increase scenarios resulted in equivalent isocline shift rates $T$ of $2 \mathrm{~km} \mathrm{yr}^{-1}, 4 \mathrm{~km} \mathrm{yr}^{-1}$ and $8 \mathrm{~km} \mathrm{yr}^{-1}$ respectively, with a standard deviation of the temperature optimum $\sigma_{d}$ of $140 \mathrm{~km}$. We then calculate the location of the optimal temperature in north-south direction $\left(Y_{\text {opt }}\right)$ in a given year $t$ as

$Y_{o p t, t}=Y_{o p t, 0}+T \times t+\sigma_{d} \times N_{t}$

with $N_{t}$ is the yearly random number drawn from a standard normal distribution and $Y_{o p t, 0}$ is the location of the optimal temperature at $t=0$.

\section{Appendix B. Supporting information}

Supplementary data associated with this article can be found in the online version at http://dx.doi.org/10.1016/j.jtbi.2015.03.019.

\section{References}

Bell, M.A., Aguirre, W.E., 2013. Contemporary evolution, allelic recycling, and adaptive radiation of the threespine stickleback. Evol. Ecol. Res. 15, 377-411.

Bourne, E.C., Bocedi, G., Travis, J.M., Pakeman, R.J., Brooker, R.W., Schiffers, K., 2014. Between migration load and evolutionary rescue: dispersal, adaptation and the response of spatially structured populations to environmental change. Proc. R. Soc. Biol. Sci. Ser. B 281, 20132795.

Brown, G.P., Shilton, C., Phillips, B.L., Shine, R., 2007. Invasion, stress, and spinal arthritis in cane toads. Proc. Natl. Acad. Sci. USA 104, 17698-17700.

Burton, O.J., Phillips, B.L., Travis, J.M.J., 2010. Trade-offs and the evolution of lifehistories during range expansion. Ecol. Lett. 13, 1210-1220. http://dx.doi.org/ 10.1111/j.1461-0248.2010.01505.x.

Channell, R., Lomolino, M.V., 2000. Trajectories to extinction: spatial dynamics of the contraction of geographical ranges. J. Biogeogr. 27, 169-179.

Chen, I.C., Hill, J.K., Ohlemueller, R., Roy, D.B., Thomas, C.D., 2011. Rapid range shifts of species associated with high levels of climate warming. Science 333, 1024-1026. http://dx.doi.org/10.1126/science.1206432.

Clobert, J., Ims, R.A., Rousset, F., 2004. Causes, mechanisms and consequences of dispersal. In: Hanski, I., Gaggiotti, O. (Eds.), Ecology, Genetics and Evolution of Metapopulations. Academic, Amsterdam.

Cobben, M.M.P., Verboom, J., Opdam, P.F.M., Hoekstra, R.F., Jochem, R., Smulders, M. J.M., 2012a. Wrong place, wrong time: climate change-induced range shift across fragmented habitat causes maladaptation and decreased population size in a modelled bird species. Glob. Change Biol. 18, 2419-2428.

Cobben, M.M.P., Verboom, J., Opdam, P.F.M., Hoekstra, R.F., Jochem, R., Smulders, M.J.M., 2012b. Landscape prerequisites for the survival of a modelled metapopulation and its neutral genetic diversity are affected by climate change. Landsc. Ecol. 27, 227-237.

Cobben, M.M.P., Verboom, J., Opdam, P., Hoekstra, R.F., Jochem, R., Arens, P., Smulders, M.J. M., 2011. Projected climate change causes loss and redistribution of genetic diversity in a model metapopulation of a medium-good disperser. Ecography 34, 920-932. http://dx.doi.org/10.1111/j.1600-0587.2011.06713.x.

Currat, M., Excoffier, L., Maddison, W., Otto, S.P., Ray, N., Whitlock, M.C., Yeaman, S., 2006. Comment on "Ongoing adaptive evolution of ASPM, a brain size determinant in Homo sapiens" and "Microcephalin, a gene regulating brainsize, continues to evolve adaptively in humans". Science 313, 172a.

Donohue, K., 1999. Seed dispersal as a maternally influenced character: mechanistic basis of maternal effects and selection on maternal characters in an annual plant. Am. Nat. 154, 674-689.

Dytham, C., Travis, J.M., Mustin, K., Benton, T.G., 2014. Changes in species' distributions during and after environmental change: which eco-evolutionary processes matter more? Ecography, http://dx.doi.org/10.1111/ecog.01194.

Edmonds, C.A., Lillie, A.S., Cavalli-Sforza, L.L., 2004. Mutations arising in the wave front of an expanding population. Proc. Natl. Acad. Sci. USA 101, 975-979.

Excoffier, L., Ray, N., 2008. Surfing during population expansions promotes genetic revolutions and structuration. Trends Ecol. Evol. 23, 347-351.

Excoffier, L., Foll, M., Petit, R.J., 2009. Genetic consequences of range expansions. Annu. Rev. Ecol. Evol. Syst. 40, 481-501. http://dx.doi.org/10.1146/annurev. ecolsys.39.110707.173414.

Gillings, S., Balmer, D.E., Fuller, R.J., 2015. Directionality of recent bird distribution shifts and climate change in Great Britain. Glob. Change Biol. , http://dx.doi.org/ 10.1111 /gcb.12823.

Haag, C.R., Saastamoinen, M., Marden, J.H., Hanski, I., 2005. A candidate locus for variation in dispersal rate in a butterfly metapopulation. Proc. R. Soc. Biol. Sci. Ser. B 272, 2449-2456. http://dx.doi.org/10.1098/rspb.2005.3235.

Hadley Centre, 2003. Climate Change. Observations and Predictions. Recent Research on Climate Change Science from the Hadley Centre, December 2003.
Hagemeijer, W.J.M., Blair, M.J., 1997. The EBCC Atlas of European Breeding Birds. T. \& A.D. Poyser.

Hampe, A., Petit, R.J., 2005. Conserving biodiversity under climate change: the rear edge matters. Ecol. Lett. 8, 461-467.

Henry, R.C., Bocedi, G., Dytham, C., Travis, J.M., 2014. Inter-annual variability influences the eco-evolutionary dynamics of range-shifting. Peer]. 1, e228.

Hewitt, G.M., 1996. Some genetic consequences of ice ages, and their role in divergence and speciation. Biol. J. Linn. Soc. 58, 247-276.

Hill, J.K., Griffiths, H.M., Thomas, C.D., 2011. Climate change and evolutionary adaptations at species' range margins. Annu. Rev. Entomol. 56, 143-159.

Ibrahim, K.M., Nichols, R.A., Hewitt, G.M., 1996. Spatial patterns of genetic variation generated by different forms of dispersal. Heredity 77, 282-291.

Imbert, E., Ronce, O., 2001. Phenotypic plasticity for dispersal ability in the seed heteromorphic Crepissancta (Asteraceae). Oikos 93, 126-134.

IPCC, 2013. Climate Change 2013: The Physical Science Basis. Summary for Policymakers. In: Stocker, T.F., Qin, D., Plattner, G.-K., Tignor, M., Allen, S.K., Boschung, J., Nauels, A., Xia, Y., Bex, V., Midgley, P.M. (Eds.), Contribution of Working Group I to the Fifth Assessment Report of the Intergovernmental Panel on Climate Change.

Klopfstein, S., Currat, M., Excoffier, L., 2006. The fate of mutations surfing on the wave of a range expansion. Mol. Biol. Evol. 23, 482-490.

Koen, E., Bowman, J., Murray, D., Wilson, P., 2014. Climate change reduces genetic diversity of Canada lynx at the trailing range edge. Ecography 37, 754-762. http://dx.doi.org/10.1111/j.1600-0587.2013.00629.x.

Kosenko, S.M., Kaigorodova, E.Y., 2001. Effect of habitat fragmentation on distribution, density and breeding performance of the middle spotted woodpecker Dendrocopos medius (Alves, Picidae) in Nerussa-Desna Polesye. Zoologichesky Zhurnal 80, 71-78.

Kosinski, Z., Ksit, P., 2006. Comparative reproductive biology of middle spotted woodpeckers Dendrocopos medius and great spotted woodpeckers D-major in a riverine forest. Bird Study 53, 237-246.

Kosinski, Z., Kempa, M., Hybsz, R., 2004. Accuracy and efficiency of different techniques for censusing territorial Middle Spotted Woodpeckers Dendrocopos medius. Acta Ornithol. 39, 29-34.

Kubisch, A., Hovestadt, T., Poethke, H.-J., 2010. On the elasticity of range limits during periods of expansion. Ecology 91, 3094-3099.

Kubisch, A., Poethke, H.J., Hovestadt, T., 2011. Density-dependent dispersal and the formation of range borders. Ecography 34, 1002-1008.

Kubisch, A., Degen, T., Hovestadt, T., Poethke, H.J., 2013. Predicting range shifts under global change: the balance between local adaptation and dispersal Ecography 36, 873-882.

Kubisch, A., Holt, R.D., Poethke, H.J., Fronhofer, E.A., 2014. Where am I and why? Synthesizing range biology and the eco-evolutionary dynamics of dispersal. Oikos 123, 5-22.

Laliberte, A.S., Ripple, W.J., 2004. Range contractions of North American carnivores and ungulates. Bioscience 54, 123-138.

Leimu, R., Fischer, M., 2008. A meta-analysis of local adaptation in plants. PLoS One 3, e4010.

Lindström, T., Brown, G.P., Sisson, S.A., Phillips, B.L., Shine, R., 2013. Rapid shifts in dispersal behavior on an expanding range edge. Proc. Natl. Acad. Sci. USA 110 13452-13456.

Michalek, K.G., Winkler, H., 2001. Parental care and parentage in monogamous great spotted woodpeckers (Picoides major) and middle spotted woodpeckers (Picoides medius). Behaviour 138, 1259-1285.

Moreau, C., Bhérer, C. Vézina, H., Jomphe, M., Labuda, D., Excoffier, L., 2011. Deep human genealogies reveal a selective advantage to be on an expanding wave front. Science 334, 1148-1150.

Nachman, M.W., Crowell, S.L., 2000. Estimate of the mutation rate per nucleotide in humans. Genetics 156, 297-304.

Parmesan, C., 2006. Ecological and evolutionary responses to recent climate change. Annu. Rev. Ecol. Evol. Syst. 37, 637-669. http://dx.doi.org/10.1146 annurev.ecolsys.37.091305.110100.

Parmesan, C., Yohe, G., 2003. A globally coherent fingerprint of climate change impacts across natural systems. Nature 421, 37-42.

Pasinelli, G., 2000. Oaks (Quercus sp.) and only oaks? Relations between habitat structure and home range size of the middle spotted woodpecker (Dendrocopos medius). Biol. Conserv. 93, 227-235.

Pearson, G.A., Lago-Leston, A., Mota, C., 2009. Frayed at the edges: selective pressure and adaptive response to abiotic stressors are mismatched in low diversity edge populations. J. Ecol. 97, 450-462.

Pettersson, B., 1985. Extinction of an isolated population of the Middle Spotted Woodpecker Dendrocopos-Medius (L) in Sweden and its relation to general theories on extinction. Biol. Conserv. 32, 335-353.

Phillips, B.L., Brown, G.P., Shine, R., 2010. Life-history evolution in range-shifting populations. Ecology 91, 1617-1627.

Phillips, B.L., Brown, G.P., Webb, J.K., Shine, R., 2006. Invasion and the evolution of speed in toads. Nature 439, 803.

Ray, N., Excoffier, L., 2009. Inferring past demography using spatially explicit population genetic models. Hum. Biol. 81, 141-157.

Rodríguez, J.P., 2002. Range contraction in declining North American bird populations. Ecol. Appl. 12, 238-248.

Roff, D.A., 1986. The evolution of wing dimorphism in insects. Evolution 40, 1009-1020. http://dx.doi.org/10.2307/2408759.

Ronce, O., 2007. How does it feel to be like a rolling stone? Ten questions about dispersal evolution. Annu. Rev. Ecol. Evol. Syst. 38, 231-253. http://dx.doi.org/ 10.1146/annurev.ecolsys.38.091206.095611. 
Schippers, P., Verboom, J., Vos, C.C., Jochem, R., 2011. Metapopulation shift and survival of woodland birds under climate change: will species be able to track? Ecography 34, 909-919.

Schluter, D., Conte, G.L., 2009. Genetics and ecological speciation. Proc. Natl. Acad. Sci. USA 106, 9955-9962.

Shine, R., Brown, G.P., Phillips, B.L., 2011. An evolutionary process that assembles phenotypes through space rather than through time. Proc. Natl. Acad. Sci. USA 108, 5708-5711. http://dx.doi.org/10.1073/pnas.1018989108.

Thomas, C.D., Franco, A., Hill, J.K., 2006. Range retractions and extinction in the face of climate warming. Trends Ecol. Evol. 21, 415-416.

Thomas, C.D., Bodsworth, E.J., Wilson, R.J., Simmons, A.D., Davies, Z.G., Musche, M. Conradt, L., 2001. Ecological and evolutionary processes at expanding range margins. Nature 411, 577-581. http://dx.doi.org/10.1038/35079066.

Travis, J., Münkemüller, T., Burton, O., 2010. Mutation surfing and the evolution of dispersal during range expansions. J. Evol. Biol. 23, 2656-2667.

Travis, J.M., Dytham, C., 2002. Dispersal evolution during invasions. Evol. Ecol. Res. 4, 1119-1129.
Travis, J.M., Münkemüller, T., Burton, O.J., Best, A., Dytham, C., Johst, K., 2007. Deleterious mutations can surf to high densities on the wave front of an expanding population. Mol. Biol. Evol. 24, 2334-2343.

Travis, J.M., Delgado, M., Bocedi, G., Baguette, M., Bartoń, K., Bonte, D., Boulangeat, I., Hodgson, J.A., Kubisch, A., Penteriani, V., 2013. Dispersal and species' responses to climate change. Oikos 122, 1532-1540.

Van Belleghem, S.M., Roelofs, D., Hendrickx, F., 2014. Evolutionary history of a dispersal-associated locus across sympatric and allopatric divergent populations of a wing -polymorphic beetle across Atlantic Europe. Mol. Ecol. 24, 890-908.

Verboom, J., Foppen, R., Chardon, P., Opdam, P., Luttikhuizen, P., 2001. Introducing the key patch approach for habitat networks with persistent populations: an example for marshland birds. Biol. Conserv. 100, 89-101.

Vos, C.C., Verboom, J., Opdam, P.F.M., Ter Braak, C.J.F., 2001. Toward ecologically scaled landscape indices. Am. Nat. 157, 24-41.

Wright, S., 1969. Evolution and the Genetics of Populations. Vol. 2. The Theory of Gene FrequenciesChicago University Press, Chicago. 